Cite this: Analyst, 2013, 138, 6097

Received 4th June 2013

Accepted 27th July 2013

DOI: $10.1039 / \mathrm{c} 3 a n 01107 \mathrm{k}$

www.rsc.org/analyst

\section{Separation of metalloproteins using a novel metal ion contaminant sweeping technique and detection of protein-bound copper by a metal ion probe in polyacrylamide gel electrophoresis: distribution of copper in human serum $\dagger$}

\begin{abstract}
Shingo Saito, ${ }^{\text {a }}$ Mitsuyoshi Kawashima, ${ }^{a}$ Hiroki Ohshima, ${ }^{a}$ Kazuki Enomoto, ${ }^{a}$ Makoto Sato, ${ }^{\mathrm{b}}$ Hajime Yoshimura, ${ }^{\mathrm{b}}$ Keitaro Yoshimoto, ${ }^{\mathrm{c}}$ Mizuo Maeda ${ }^{\mathrm{d}}$ and Masami Shibukawa ${ }^{a}$

A polyacrylamide gel electrophoresis (PAGE)-based method has been developed, consisting of two types of gel electrophoresis, to obtain an accurate distribution of protein-bound metal ions in biological samples. First, proteins are separated by PAGE without the uptake of contaminant metal ions in the separation field and dissociation of metal ions from the proteins. This is followed by another PAGE for the separation and detection of protein-bound metal ions in small volume samples with high sensitivity in the ppt range using a fluorescent metal probe. The former is a new technique using blue-native (BN) PAGE to electrophoretically sweep all metal contaminants by employing two kinds of chelating agents. These agents form complexes with contaminants in the gel and the separation buffer solution, which migrate towards opposite pole directions, thus lowering the contaminants to below the ppt level during separation. This is termed "Metal Ion Contaminant Sweeping BN-PAGE (MICS-BN-PAGE)". After the separation of proteins under these first metal-free conditions, the metal ions in the gel fractions are eluted, followed by derivatization of copper ions into the metal probe complexes to be separated and determined by fluorescence detection in the second PAGE. In this PAGE-based method, the copper ions bound to ceruloplasmin and superoxide dismutase were quantitatively determined, in addition to the exchangeable albumin-bound copper ions. This system successfully provided distribution maps of protein-copper in human serum. The precise distribution of copper in human serum was investigated, and found to be different from that which is widely accepted.
\end{abstract}

\section{Introduction}

The identification and detection of metalloproteins has recently attracted a lot of interest, since knowing which proteins bind to which metal ions in biological samples is key to understanding many biological processes involving metal ions. ${ }^{1-6}$ Various methods that enable the detection of metalloproteins have been proposed: ${ }^{7-10}$ high-performance liquid chromatography (HPLC), ${ }^{11,12}$ capillary electrophoresis (CE $)^{13-16}$ and polyacrylamide

${ }^{a}$ Graduate School of Science and Engineering, Saitama University, 255 Shimo-Okubo, Sakura-ku, Saitama 338-8570, Japan. E-mail: shingo@apc.saitama-u.ac.jp; Tel: +81 488583559

${ }^{b}$ Sagamihara R\&D Center, Shino-Test Corporation, 2-29-14, Oonodai, Minami-ku, Sagmihara-shi, Kanagawa 252-0331, Japan

${ }^{c}$ Graduate School of College of Arts and Sciences, University of Tokyo, 3-8-1 Komaba, Meguro-ku, Tokyo, 153-8902, Japan

${ }^{d}$ Bioengineering Laboratory, RIKEN, 2-1 Hirosawa, Wako, Saitama 351-0198, Japan

$\dagger$ Electronic supplementary information (ESI) available. See DOI: 10.1039/c3an01107k gel electrophoresis (PAGE)-based techniques ${ }^{17-23}$ combined with instrumental elemental analysis methods, such as inductively coupled plasma atomic emission spectroscopy (ICP-AES), ICPmass spectroscopy (MS), and radioautography. While these methods are very useful for investigating the distribution of metal ions in various biological samples, they do present some difficulties.

HPLC-based methods ${ }^{24-26}$ are disadvantageous in that the interaction between the proteins and the hydrophobic stationary phase frequently causes denaturing of the proteins, which leads to dissociation of the metal ions. While size-exclusion HPLC (SEC) results in less denaturing of proteins due to weak interactions between proteins and the stationary phase, the resolution between the proteins is insufficient, frequently resulting in coelution of various proteins. ${ }^{26-28}$ The CE-based method, which allows high resolution among proteins, has rather poor detection sensitivity for metal ions due to an innate and very small injection volume. Several research groups have developed PAGE-based techniques combined with laser-ablation (LA)-ICP-MS. ${ }^{29-32}$ 
Reasonable separation efficiencies have been obtained using these methods (with the typical number of theoretical plates for albumin in SEC, ion-exchange LC, CE and PAGE being 200, ${ }^{33}$ $300,{ }^{25} 2700$ (ref. 13) and 1200 (in this study)), with some suppression of the dissociation of metal ions from metalloproteins having been reported using the blue native (BN)-PAGE technique. ${ }^{30,31}$ However, it has been pointed out that LA-ICP-MS has poor sensitivity and irreproducibility due to the gel drying procedure and the heterogeneous surface of the gel. ${ }^{29,31,32}$ In terms of sensitivity, while the metal concentration of minor metalloproteins in biological samples is in the ppb range or lower (major metalloproteins have metal ions near the ppm level), a metal detection method at the ppt to the sub-ppb level in a small volume $(\sim 100 \mu \mathrm{L})$ is required due to dilution of the samples during separation and/or fractionation in the presence of large excesses of other proteins.

In addition to these difficulties, a pitfall of all of HPLC, CE, and PAGE-based separation methods is that of contaminant metal ions. ${ }^{30,32}$ The existence of contaminant metal ions in analytical systems causes some serious problems. First, their presence results in high background noise for metal detection, namely, a high blank signal, which is usually on sub-ppb levels or higher. ${ }^{2}$ Due to the overlapping of this background noise with analyte signals, sensitive detection below the lower ppb range is impossible, and the concentrations of minor metalloproteins in biological samples are frequently in the low ppb range or less. Second, contaminant metal ions could accelerate metalexchange processes with metalloproteins during separation, thereby resulting in a low estimate of the content of proteinbound metal ions. Third, some free proteins would bind to contaminant metal ions during migration, that is, uptake of the metal ions by apo-proteins would occur, leading to false positive detection and overestimation. These problems ensure that accurate determination of the distributions of protein-bound metal ions is difficult, particularly when determining trace metalloproteins. The amount of human serum albumin-bound copper $(\mathrm{HSA}-\mathrm{Cu})$ in human serum, which is reported to be an exchangeable metal species in human serum, has various values (3-20\% total copper), depending on the analytical methods ${ }^{34}$ (vide infra).

Here, we present a set of two novel PAGE-based techniques with high sensitivity for metal ions in small volume samples, and no contamination was found during protein separation. One technique is a determination method using PAGE for metal ions (particularly copper ions) in the ppt range in $\sim 100 \mu \mathrm{L}$ samples eluted from the gel fraction. This method is low-cost, robust, high-throughput ${ }^{35}$ and maintenance-free. The other technique is a contaminant metal-free BN-PAGE system, which provides protein separation without dissociation of the proteinbound metal ions and uptake of contaminant metals. Combined use of the two techniques successfully produced PAGE-based protein-copper maps to provide more accurate metal distribution information than previously reported. The proteins in the biological samples were separated using BN-PAGE with no contaminant metal ions, followed by elution of the metal ions by acid from cut gel fractions at $2.5 \mathrm{~mm}$ intervals. The metal ions in the eluted solution that included proteins were derivatized with fluorescent probes to yield fluorescent complexes. Thereafter, the metal complex solutions were re-concentrated and separated from metal ions and free emissive probes by the second PAGE (see Fig. S1†).

The distribution of copper ions in human serum is very important since copper ions are highly toxic ${ }^{36}$ and are strongly associated with metabolic disorders of copper such as Wilson disease, ${ }^{37}$ Menkes disease, aceruloplasminemia, and cancer, ${ }^{38}$ as well as neurodegenerative disorders such as Parkinson's disease (PD) ${ }^{\mathbf{3 9 , 4 0}}$ and Alzheimer disease (AD). ${ }^{\mathbf{4 1 , 4 2}}$ Copper distribution has been investigated by many researchers using various methods: ICP-MS after filtration, ${ }^{26}$ HPLC-ICP-MS, ${ }^{34,43}$ solvent extraction, ${ }^{44}$ GPC-AAS ${ }^{38}$ and isotope dilution. ${ }^{45}$ Summarizing these reports, ${ }^{46}$ the widely accepted populations of copper in human serum are $65-70 \%$ as ceruloplasmin-bound ( $\mathrm{Cp}-\mathrm{Cu}$ ), $3-18 \%$ as human serum albumin-bound copper (HSA-Cu), and $0-9 \%$ as transcuprein-bound copper (Tc-Cu). Since the concentrations of the non-ceruloplasmin copper, which is termed as loosely bound $\mathrm{Cu}$, exchangeable $\mathrm{Cu}(\mathrm{Ex} \mathrm{Cu})$, or free $\mathrm{Cu}$, are much lower than those of $\mathrm{Cp}-\mathrm{Cu}$, the determination of $\mathrm{Ex} \mathrm{Cu}$ is still challenging. It has been suggested that most non$\mathrm{Cp}-\mathrm{Cu}$ binds to HSA in serum, ${ }^{\mathbf{4 7}}$ and while transcuprein (Tc) is also a copper binding protein in plasma, most Tc seems to be trapped in clots to be removed from serum. ${ }^{48}$ However, there have been no reports on the quantitative determination of non$\mathrm{Cp}-\mathrm{Cu}$ complexes, including the HSA-Cu complex in serum due to dissociation of $\mathrm{Cu}$ ions from the HSA complex during separation. That is, there has been no direct evidence for the existence of $\mathrm{HSA}-\mathrm{Cu}$ in human serum so far. In this study, we proposed a new method, Metal Ion Contaminant SweepingBN-PAGE/metal detection PAGE, to investigate the distribution of copper ions in human serum more accurately by controlling the dissociation of Ex-Cu (HSA-Cu).

\section{Experimental}

\section{Chemicals}

The fluorescence metal probe (FTC-ABDOTA, see Fig. 1 for the chemical structure) for metal detection PAGE was synthesized as reported previously. ${ }^{49}$ An appropriate amount of powder probe was dissolved in ultrapure water (produced by DirectQ UV, Nihon Millipore, Tokyo, $>18.2 \mathrm{M} \Omega \mathrm{cm}$ ) to form a $2 \times 10^{-3} \mathrm{M}$ stock solution. If not otherwise specified, all reagents employed in this study were of analytical or electrophoresis grade. For gel casting, monomer stock solutions were prepared by dissolving appropriate amounts of acrylamide (AA) (Tokyo Kasei, Tokyo, Japan; $>98 \%$ purity) and $N, N^{\prime}$-methylenebisacrylamide (Bis) (Wako Pure Chemicals Industries, Ltd., Tokyo, Japan; 99\% purity) in ultrapure water to a concentration of $60 \% \mathrm{~T}$ and $2.7 \%$ $\mathrm{C}$, respectively. Solutions of $10 \%$ ammonium persulfate (APS, Kishida Chemical Co. Ltd., Japan) and $N, N, N^{\prime}, N^{\prime}$-tetramethylethylenediamine (TEMED, Acros Organics, Geel, Belgium) used for acceleration of polymerization were prepared at the time of use. Stock solutions of tris(hydroxymethyl)aminomethane (Tris)-HCl and Tris-glycine $\mathrm{pH}$ buffer were prepared by dissolving appropriate amounts of Tris and glycine powder (SigmaAldrich, $>99 \%$ purity) in ultrapure water with the addition of 
ultrapure concentrated hydrogen chloride solution (20\% solution, Tama Pure Chemicals, Japan) to the desired pH. Chelating agents for the MICS technique, disodium ethylenediamine$N, N, N^{\prime}, N^{\prime}$-tetraacetate dehydrate (EDTA, $>99.5 \%$ purity), $N, N, N^{\prime}, N^{\prime}$-tetrakis(2-pyridiylmethyl)ethylenediamine (TPEN, $>97 \%$ purity) and trans-1,2-diaminocyclohexane- $N, N, N^{\prime}, N^{\prime}$-tetraacetic acid monohydrate (CyDTA) were purchased from Dojindo (Kumamoto, Japan). Proteins (HSA ( $>95 \%$ purity), superoxide dismutase (SOD) from bovine erythrocytes $(\mathrm{Cu} / \mathrm{Zn}$ type) purchased from Wako Pure Chemical Industries Ltd., human Cp, and metallothionein (MT) type I from rabbit liver purchased from Sigma) were dissolved in pure water to appropriate concentrations. All protein and serum sample solutions were stored at $-40{ }^{\circ} \mathrm{C}$ to prevent denaturation of the proteins..$^{45}$ Bromophenol blue (BPB, $0.1 \mathrm{w} / \mathrm{v} \%$, Wako Pure Chemical Industries Ltd.), Orange G (0.1 w/v\%, Tokyo Kasei) and molecular weight protein standard (Precision Plus Blue Standard, BioRad Laboratories) were used as markers for PAGE. Standard metal ion solutions ( $\mathrm{Fe}, \mathrm{Cu}, \mathrm{Zn}, \mathrm{Ni}, \mathrm{Co}, \mathrm{Mn}, \mathrm{Cd}$ and $\mathrm{Hg}$ ) at $1000 \mathrm{ppm}$ were purchased from Wako Pure Chemical Industries Ltd. Human blood samples ( $n=10$; healthy individuals) were collected in a vacuum blood collection tube, Venoject VP-P070K30 (Terumo, Tokyo, Japan). After a standing time of $3 \mathrm{~h}$, the samples were centrifuged for $20 \mathrm{~min}(3000 \mathrm{rpm}$, RCF $2500 \mathrm{~g}$ ). Human serum (the supernatant liquid) was collected and stored at $-40{ }^{\circ} \mathrm{C}$ to prevent denaturation.

\section{Apparatus}

A set of Protean XL slab gels $(20 \times 20 \mathrm{~cm}$ inner plate, $22.3 \times 20$ $\mathrm{cm}$ outer plate, $0.5 \mathrm{~mm}$ spacer) and a PowerPack HV high voltage power supply (Bio-Rad Laboratories) were employed for the PAGE experiments. For the gel images (absorbance for protein detection and fluorescence for metal detection), we use the gel documentation system of Printgraph AE-9633FXFC-U (Atto Corp., Japan) equipped with a monochrome CCD camera and photo-diode light sources, Gel Viewer FP 401B (Atto Corp., Japan; brightness, $1800 \mathrm{nt}$; color temperature, $6100 \mathrm{~K} ; 10 \mathrm{~W}$ ) for absorption images and Safe Imager (Invitrogen, Carlsbad, NM, $\lambda_{\mathrm{ex}}=470 \mathrm{~nm}, 30 \mathrm{~W}$ ) for fluorescent images. The exposure time was set to $0.5-2.0 \mathrm{~s}$. The gel images were analyzed by using CS Analyzer 3 software (Atto). A Typhoon 9400 model confocal laser scanning system (GE Healthcare Japan, Tokyo) was also used with a $520 \mathrm{~nm}$ bandpass filter and excitation by an Ar laser at $488 \mathrm{~nm}$. A Perkin-Elmer Optima 5300 DV ICP-atomic emission spectrometer (AES) was used to determine the metal contamination concentrations in the reagents.

\section{Procedure}

First dimension (metal ion contaminant sweeping (MICS)blue native (BN)-polyacrylamide gel electrophoresis (PAGE)). A degassed monomer solution of separation gel $(10 \% \mathrm{~T} / 2.7 \% \mathrm{C} \mathrm{AA} /$ Bis, $190 \mathrm{mM}$ Tris-HCl (pH 8.8), $10 \mu \mathrm{M}$ EDTA), prepared by adding $100 \mu \mathrm{L}$ of $10 \%$ APS and $20 \mu \mathrm{L}$ of TEMED for polymerization, was cast between glass plates and gelated for $2 \mathrm{~h}$. A stacking gel (3.9\%T/2.7\%C AA/Bis, $63 \mathrm{mM}$ Tris-HCl (pH 7.4), $10 \mu \mathrm{M}$ EDTA) was subsequently prepared using a well comb on the separation gel in a similar way. The lengths of the separation and stacking gels were 16 and $1.5 \mathrm{~cm}$, respectively. Samples of standard proteins and human serum were prepared by mixing solutions of $6.3 \%$ glycerol, $3.0 \mathrm{mM}$ Tris- $\mathrm{HCl}$ (pH 7.4), and 3.0 mM CBB G-250 with appropriate amounts of standard proteins or human serum (50\% volume of applied sample solutions). The gel was conditioned by applying $400 \mathrm{~V}$ for 20 min with an upper and lower migration buffer solution of 6.3 $\mathrm{mM}$ Tris- $\mathrm{HCl}(\mathrm{pH}$ 7.4) including $10 \mu \mathrm{M}$ TPEN, and $6.3-48 \mathrm{mM}$ Tris-gly (pH 8.6) including $10 \mu \mathrm{M}$ CyDTA, respectively, prior to sample injection, to sweep contaminant metal ions towards both the negative and the positive poles for preparation of a metal-free stacking gel (vide infra). The prepared sample solution $(10 \mu \mathrm{L})$ was injected into the wells after careful rinsing to remove all TPEN and the upper buffer solution was exchanged by a Tris-gly (3.1-24 mM, pH 8.6) buffer solution without TPEN. A voltage of $600 \mathrm{~V}$ was then applied for 3 min to move the sample proteins into the concentration gel (about $2 \mathrm{~mm}$ ). Subsequently, electrophoresis was conducted at $600 \mathrm{~V}$ for $2 \mathrm{~h}$ after exchanging an upper buffer solution with $10 \mu \mathrm{M}$ TPEN (6.3-4.8 mM Tris-gly, pH 8.6). All electrophoresis runs were conducted in an incubator (MIR-252, SANYO Electric, Osaka, Japan) at $268 \mathrm{~K}$ with a cooling core set in the electrophoresis apparatus equipped with a constant temperature circulator (LTB-125, AS ONE, Osaka, Japan), to keep the temperature of the slab gel constant at $273 \mathrm{~K}$. A gel image was obtained by using a CCD camera after the first dimension (protein separation).

Elution of copper ions and second dimension (metal detection PAGE using a fluorescent probe). The separation gel was cut at intervals of $2.5 \mathrm{~mm}$ ( $2 \mathrm{~cm}$ width) prior to acid extraction of copper ions bound to proteins by shaking the fraction in $100 \mu \mathrm{L}$ of $0.2 \mathrm{M}$ pure hydrochloride solution for $2 \mathrm{~h}$. Thereafter, solutions of FTC-ABDOTA $(50 \mu \mathrm{M}, 1 \mu \mathrm{L})$, Tris-HCl (pH 10, $1.5 \mathrm{M}, 5 \mu \mathrm{M}$ ), and glycerol were sequentially added to the eluted solutions $(25 \mu \mathrm{L})$ from the gel fraction to the concentrations of $1.0 \mu \mathrm{M}, 0.15 \mathrm{M}$ and $2.5 \%$, respectively, in $50 \mu \mathrm{L}$ (the diluted factor of the original sample solution was 16). The mixed sample solution was incubated for $30 \mathrm{~min}$. The prepared sample solution $(10-100 \mu \mathrm{L})$ was injected into the well in the second dimension gel $(10 \% \mathrm{~T} / 2.7 \% \mathrm{C} \mathrm{AA} / \mathrm{Bis}, 94 \mathrm{mM}$ Tris$\mathrm{HCl}, \mathrm{pH} 8.8)$ and a separation gel $(30 \% \mathrm{~T} / 2.7 \% \mathrm{C} \mathrm{AA} / \mathrm{Bis}, 94 \mathrm{mM}$ Tris- $48 \mathrm{mM}$ glycine, $\mathrm{pH}$ 9.4) using a $6.3 \mathrm{mM}$ Tris- $48 \mathrm{mM}$ glycine migration buffer solution $(10 \mu \mathrm{M}$ CyDTA was added to the lower migration buffer). It should be noted that no fluorescent probe was added to migration buffer solutions; i.e. no complexation equilibrium occurs between metal ions and the probe during migration. A typical high voltage of $1300 \mathrm{~V}$ was used for electrophoresis for $1-4 \mathrm{~h}$ at $4{ }^{\circ} \mathrm{C}$. The bands of metal ions were determined by fluorescence detection using a CCD camera with a photodiode excitation light source.

\section{Results and discussion}

\section{Metal ion detection PAGE using a fluorescence probe}

In metal detection PAGE, stacking and separation gels are employed. A discontinuous gel system is very useful because it can re-concentrate the diluted samples $(\sim 100 \mu \mathrm{L})$ after extraction 


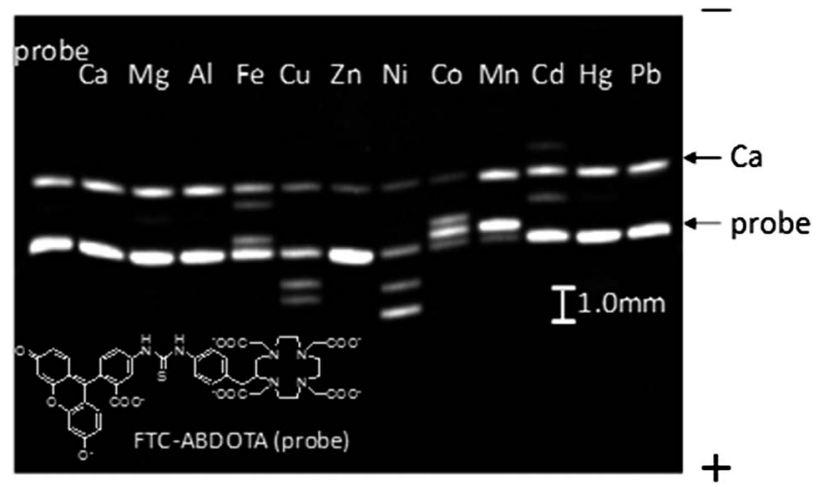

Fig. 1 Typical electrophoretogram using the metal probes in PAGE. Stacking gel, $16.5 \% \mathrm{~T} / 2.7 \% \mathrm{C} \mathrm{AA} / \mathrm{Bis}$, Tris-HCl $(94 \mathrm{mM}, \mathrm{pH} 8.85)$ ); separation gel, AA/Bis (30\%T, $2.7 \% \mathrm{C})$, Tris-glycine (94-48 mM, pH 9.4); buffer solution, Tris-glycine (6.3-48 $\mathrm{mM}, \mathrm{pH}$ 8.6); applied current constant of $30 \mathrm{~mA}$; temperature constant of $4^{\circ} \mathrm{C}$; migration for $2.5 \mathrm{~h}$. Sample $(10 \mu \mathrm{L}),\left[\mathrm{M}^{2+}\right]=1.0 \times 10^{-6} \mathrm{M},[\mathrm{L}]=1.0 \times 10^{-5} \mathrm{M}_{\text {, }}$ $[$ Tris- $\mathrm{HCl}]=75 \mathrm{mM}(\mathrm{pH} \mathrm{8.8)}$, [glycerol] $=2.5 \% \mathrm{v} / \mathrm{v}$.

from small gel fractions (the volume of bands or spots are usually some tens of $\mu \mathrm{L}$ in PAGE). The well-known Laemmli ${ }^{50}$ and Ornstein-Davis buffer systems, ${ }^{51}$ which were designed for concentration and separation of proteins using Tris- $\mathrm{HCl}$ as the gel buffer (pH 6.8 and pH 8.8 for the stacking and separation gel, respectively) and Tris-gly as the migration buffer, were initially examined for metal-probe complex samples. Although the samples were stacked in thin bands, less than $1 \mathrm{~mm}$ wide based on the isotachophoresis mechanism,$^{52}$ the stacking mode was not canceled after migration into the separation gel, i.e., the separation mode did not commence like that of the protein. This is due to the different stacking mechanisms between the proteins and the probe complex. For proteins, the change of mobility due to $\mathrm{pH}$ jump from the stacking gel ( $\mathrm{pH}$ 6.8) to the separation gel ( $\mathrm{pH}$ 8.8) causes a change in the order of mobility for the isotachophoretic concentration: ${ }^{22}-\mu_{\text {glycine }}<-\mu_{\text {protein }}<-\mu_{\mathrm{Cl}}$ in the stacking gel for concentration and $-\mu_{\text {protein }}<-\mu_{\text {glycine }}<-\mu_{\mathrm{Cl}}$ in the separation gel due to the acid-dissociation of glycine $\left(\mathrm{p} K_{\mathrm{a} 2}=9.66\right)$ for separation. ${ }^{30}$ For metal-probe complexes, it seemed that the order did not change, $-\mu_{\text {glycine }}<-\mu_{\text {probe }}<-\mu_{\mathrm{Cl}}$, at both $\mathrm{pH} 6.8$ and 8.8, leading to the isotachophoretic stacking. This problem was resolved by a transient isotachophoresis technique: glycine was added to the separation gel. This caused disorder of the mobility since glycine exists ubiquitously in the separation gel so that transition from the stacking mode to the separation mode takes place. A 40-fold concentration enhancement was observed when $100 \mu \mathrm{L}$ of the sample was injected.

It was reported that it is very difficult to achieve separation of metal-probe complexes using the usual zone electrophoresis since they possess a very similar charge/size ratio among different center-metal ions. ${ }^{49,53-55}$ In fact, the mobility of the probe complex is the same when using the usual total gel concentrations $(5-10 \% \mathrm{~T}$ ) in the separation gel (see Fig. S2 $\dagger$ ). However, the resolution among the metal-probe complexes dramatically increased when an unusually high concentration gel $(20-30 \% \mathrm{~T})$ was employed (Fig. S2 $\dagger$ ). It is interesting to note that the separation of small molecules can be controlled by the gel concentration without any other manipulation. ${ }^{49,53,55}$ The results of the metal-probe complexes in PAGE with $30 \% \mathrm{~T} / 2.7 \%$ $\mathrm{C}$ are shown in Fig. 1. The metal ions of $\mathrm{Fe}^{2+}, \mathrm{Cu}^{2+}, \mathrm{Ni}^{2+}, \mathrm{Co}^{2+}$ and $\mathrm{Cd}^{2+}$ were separated without dissociation during the separation process. In contrast, it is reported that a metal complex dissociates into the free metal ion and free ligand (probe) in the separation fields of CE or HPLC, resulting in the disappearance of the metal complex peaks in the electropherogram, if the complex is kinetically labile. ${ }^{49,53,54,56,57}$ Our results indicate that the metal-probe complexes detected in these experiments were kinetically inert. The metal ions were detected with direct fluorescence since the probe was specifically designed to show emission with or without complexation with heavy and paramagnetic metal ions, ${ }^{49,54,58}$ while these metal ions generally have the quenching effect of a fluorophore in a ligand. Direct fluorescence detection of heavy metal ions in separation methods is rare and no studies have taken place using PAGE to our knowledge. While two bands for one metal ion and a free probe were observed for $\mathrm{Fe}^{2+}, \mathrm{Cu}^{2+}, \mathrm{Ni}^{2+}$, and $\mathrm{Cd}^{2+}$, these appeared to be due to a structural isomer of the metal complex and contaminant calcium in the buffer, respectively, according to a previous report. ${ }^{49}$

The control of such high resolution among the metal ions (Fig. 1) may be due to several possible factors. One is the molecular sieving effect. The dependence of the resolution on the gel concentration was investigated, and the pore radius in the gel was estimated according to equations reported by Holms and Stellwagen ${ }^{59,60}$ (see Fig. S2 $\dagger$ ). Decreasing the pore size (40$101 \mathrm{~nm})$ and increasing the total gel concentration $(5-30 \% \mathrm{~T} /$ $2.7 \% \mathrm{C}$ ) resulted in a higher resolution, while not even a slight separation was achieved with the smallest pore size with high concentration of the cross-linker (estimated pore size: $29 \mathrm{~nm}$, Fig. S2e $\dagger$ ). In addition, the mobility of the metal-probe complex was independent of the degree of cross-linking (Fig. S3†). As such, the sieving effect does not seem to work in the separation of metal complexes. Another possibility is the adsorption of the probe complexes on acrylamide residues in the gel. If adsorption should take place, the resolution would change depending on the gel concentration, and the mobility of the probe complexes would decrease with increasing gel concentration because the number of adsorption sites increases. However, the constant mobility of the probe complexes was observed at over $15 \% \mathrm{~T}$ in experiments using capillary gel electrophoresis (data not shown). Based on this fact, few adsorptions onto the residue in the gel seemed to occur. Another explanation for the separation mechanism is the effect of unusual water in the nanopores. Shibukawa et al. reported that the selectivity of various small water-soluble molecules in gel filtration chromatography depends on the amount of solutes in the freezable bound water and non-freezable water as opposed to the bulk water that functions as a stationary phase in water-swollen hydrophilic polymer gels including polyacrylamide gel, and suggested that the water differs from the usual bulk water in hydrophilic gels. ${ }^{61,62}$ It has also been reported that water in a nanotube has high viscosity and low polarity, and stabilizes the hydration structure of a protein. ${ }^{63}$ Although the detailed separation 
mechanism is beyond the scope of this work, the separation of small molecules in nanopores is an interesting subject.

The detection limits (DLs) in the metal detection PAGE were determined for metal ions completely separated using both the CCD camera with the transilluminator and the fluorescence imager with an Ar laser and are summarized in Table 1 (see Fig. S4 for the calibration curve and electropherogram $\dagger$ ). Even using excitation by the transilluminator, high sensitivity for sub-ppb (nM order) was accessible and sensitivity reached the ppt range (or sub-femtomol) using a confocal laser scanning system. Such high sensitivity without employing large analytical instruments such as ICP-MS is useful for a biochemist familiar with low-cost PAGE.

The metal detection PAGE system was applied to some metalloprotein standard solutions and a standard human serum sample to confirm whether this system would work for biological samples. Solutions of Cp, SOD, HSA and MT, and a human serum sample were examined to determine the total copper and cadmium concentrations in metal-binding proteins and in a real biological sample. The results obtained are summarized in Table S1. $\uparrow$ The values determined were almost identical to the concentrations determined by ICP-AES. These results suggest that this type of PAGE is suitable for the detection of metal ions with higher affinity to metal ions than the coexisting metal-binding proteins. These results are reasonable considering the higher affinity of DOTA towards metal ions (log $K_{\mathrm{M} \text {-DOTA }}=22.3,21.3 \mathrm{M}^{-1}$ for $\mathrm{Cu}^{2+}, \mathrm{Cd}^{2+}$, respectively) ${ }^{64}$ than the

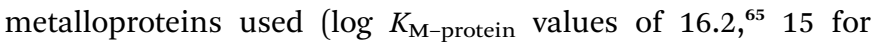
HSA-Cu, SOD-Cu and MT-Cd). ${ }^{66}$

\section{Metal ion contaminant sweeping (MICS)-blue native (BN)- polyacrylamide gel electrophoresis (PAGE)}

The metal detection PAGE (as described above) was applied as the second dimension to the sample solutions, which were extracted by $0.2 \mathrm{M} \mathrm{HCl}$ from cut gel fractions $(25 \mu \mathrm{L})$ after conventional BN-PAGE of human serum samples. ${ }^{67}$ Since some researchers have reported that metal ions strongly binding to proteins do not dissociate during migration using BN-PAGE, ${ }^{\mathbf{3 0 , 3 1}}$ it was expected that the distribution of the metal ions could be obtained by combining BN-PAGE and metal detection PAGE. The electropherogram (a protein-metal map) obtained is shown in Fig. 2. No cadmium and nickel ions were detected in the

Table 1 Detection limits of metal ions ( $\mathrm{M}$ and $\mathrm{ppb}$ ) in $10 \mu \mathrm{L}$ sample solutions as determined with a CCD camera with a transilluminator and a laser-excitation imager $^{a}$

\begin{tabular}{lll}
\hline $\begin{array}{l}\text { Metal } \\
\text { ion }\end{array}$ & $\begin{array}{l}\text { Detection by a CCD camera/ } \\
\mathrm{M}(\mathrm{ppb}, \text { amount/pg) }\end{array}$ & $\begin{array}{l}\text { Detection by a laser-excitation } \\
\text { imager/M }(\mathrm{ppb}, \text { amount/pg) }\end{array}$ \\
\hline $\mathrm{Fe}$ & $3.3 \times 10^{-9}(0.18,1.8)$ & $1.9 \times 10^{-10}(0.010,0.10)$ \\
$\mathrm{Cu}$ & $2.6 \times 10^{-9}(0.17,1.7)$ & $7.8 \times 10^{-11}(0.0051,0.051)$ \\
$\mathrm{Ni}$ & $3.8 \times 10^{-9}(0.22,2.2)$ & $2.1 \times 10^{-10}(0.012,0.12)$ \\
$\mathrm{Co}$ & $3.2 \times 10^{-9}(0.19,1.9)$ & $1.2 \times 10^{-10}(0.007,0.07)$ \\
$\mathrm{Cd}$ & $7.4 \times 10^{-9}(0.83,8.3)$ & $2.2 \times 10^{-10}(0.025,0.25)$
\end{tabular}

${ }^{a}$ The detection limits were determined based on the $3 \sigma$ of blank. Linearity was obtained from 0.1 to $100 \mathrm{ppb}$. fractions, since the amounts of $\mathrm{Cd}$ and $\mathrm{Ni}$ in human serum are generally very small. Iron, cobalt and manganese ions were also not detected due to interference from the rather thick bands of the free probe since a large excess of the probe $\left(5 \times 10^{-6} \mathrm{M}\right)$ had to be employed for quantitative derivatization (total $\mathrm{Fe}$ and $\mathrm{Cu}$ concentration expected was up to the $\mu \mathrm{M}$ level in the gel fraction for a human serum sample). Copper ions were successfully detected in the human serum sample. However, they were detected in many gel fractions, while the ceruloplasmin-bound copper ( $\mathrm{Cp}-\mathrm{Cu})$ was detected as expected (see Fig. 2). If this measurement was accurate, the summation of the amount of $\mathrm{Cu}$ in each gel fraction would correspond to the total concentration of $\mathrm{Cu}$ in the serum. The recovery of total $\mathrm{Cu}$ in this method based on the summation was $643 \%(6.1 \mathrm{ppm} \mathrm{Cu})$ compared to the total $\mathrm{Cu}$ obtained by ICP-AES $(0.95 \mathrm{ppm} \mathrm{Cu})$. Meanwhile, since the quantitative extraction of copper ions from gel fractions was confirmed by a recovery test adding copper standard solution to the gel monomer solution prior to polymerization (98 $\pm 9.4 \%, n=6$, data not shown), this BN-PAGE/metal detection PAGE system seemed to work.

As such, since serious contamination by $\mathrm{Cu}$ ions was expected for this method, each instrument and procedure was verified in detail in terms of metal contamination. The results of a comprehensive investigation into contaminant $\mathrm{Cu}$ and $\mathrm{Fe}$ (in polyacrylamide gel, migration buffer reagents, vacuum blood collection tubes employed, etc.) showed serious metal contamination from the gel in the ppb range, and migration buffer solutions at sub-ppb levels (see Table $\mathrm{S} 2 \dagger$ and footnotes in ref. 68 and 69). According to a blank test result (metal detection PAGE of gel fractions in BN-PAGE with water sample injection, see Fig. $\mathrm{S} 5 \dagger$ ), an average $\mathrm{Cu}$ concentration of $7.5 \pm 1.7$ ppb per single fraction was found. This concentration level agrees well with the contamination levels in the reagents employed. The proteins may have been separated in the separation media including metal contamination in the $\mathrm{ppb}$ range by various methods previously reported, such as PAGE and LC using high concentration buffers and/or gels comprised of even analytical grade reagents. Although serious contamination might render accurate measurements of the distribution of metals impossible due to the high background, uptake of metals into proteins and acceleration of metal-exchange reactions of metalloproteins during migration or elution (see the footnote in ref. 70), this essential problem remains unresolved. In terms of the metal contamination problem, the uptake of contaminant

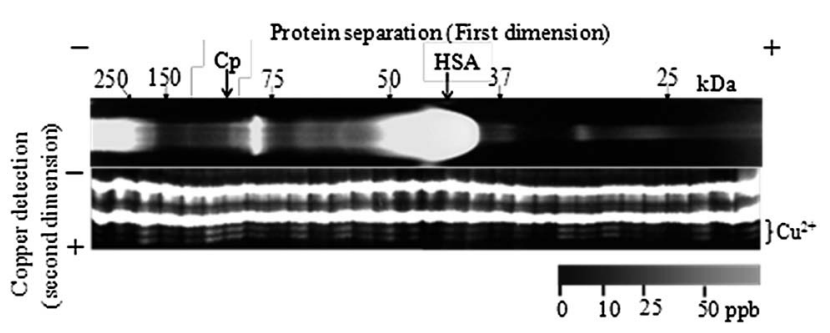

Fig. 2 Detection of copper ion in gel fractions of conventional BN-PAGE. Sample: human serum from a healthy male, age 48 . Recovery (summation of each fraction/ total $\mathrm{Cu}$ concentration in the serum sample $=6.13 \mathrm{ppm} / 0.95 \mathrm{ppm}$ ) was $643 \%$. 
$\mathrm{Cu}$ by HSA during separation was estimated on the basis of equilibrium calculations (see ESI $\dagger$ ), which implies that sub-ppb contamination in the separation buffer solution in LC or electrophoresis provides a ppb range of uptake even under optimistic estimations. In the case of our PAGE, contaminant $\mathrm{Cu}$ ions possibly exist in the form of $\left[\mathrm{Cu}-(\text { Tris })_{4}\right]^{2+}$ in the gel and the lower (anode) buffer solution, and $\left[\mathrm{Cu}-(\text { glycine })_{3}\right]^{-}$in the upper (cathode) buffer solution judging from their stability constants $\left(K_{\mathrm{Cu}-\text { Tris4 }}=10^{14.1} \mathrm{M}^{-4}, K_{\mathrm{Cu}-\text { gly3 }}=10^{16.96} \mathrm{M}^{-4}\right) .{ }^{71,72}$ Each complex could migrate toward the upper (cathode) and lower (anode) directions, respectively (Fig. S6a $\dagger$ ). This implies that the contaminant $\mathrm{Cu}$ complexes in the buffer solutions are always supplied from both the upper and lower buffer reservoirs into the gel during migration due to the electrical charges of the contaminant metal complexes, i.e., this migration of contaminant metals would also provide a ppb level of contamination.

With the metal contamination problem in mind, we developed a new metal contamination-free PAGE, termed Metal Ion Contaminant Sweeping (MICS)-BN-PAGE (see the Experimental section for the procedure), which could completely avoid the contact of metalloproteins with contaminant metal ions during migration. The method, applied in the first dimension prior to metal detection PAGE, consists of three stages (see Fig. S6b-d $\dagger$ ). First, we prepared stacking and separation gels including EDTA for masking the contaminant metal ions, followed by conditioning with an upper buffer solution including TPEN by applying voltage. This operation sweeps all contaminant metal ions in the stacking gel toward the lower solution, and the metal contaminants in the upper buffer solution could not migrate into the gel during conditioning because each contaminant metal (mostly transition metal ions) forms anionic $\left[\mathrm{M}^{2+/ 3+}\right.$ EDTA $\left.^{4-}\right]^{2-/-}$ complexes in the gel or cationic $\left[\mathrm{M}^{2+/ 3+}-\mathrm{TPEN}\right]^{2+/ 3+}$ complexes in the upper buffer solution with very high thermodynamic $^{64,73}\left(\log K_{\mathrm{ML}} \sim 25\right)$ and kinetic stability. ${ }^{53,56,57}$ Second, the sample was applied with a TPEN-free upper buffer solution (buffer reagents were diluted to prevent serious contaminant metal ions) to avoid the ligand-exchange reaction of metalloproteins with TPEN with high affinity to transition metal ions. ${ }^{73}$ Applying voltage for a short time ( $\left.600 \mathrm{~V}, 3 \mathrm{~min}\right)$ made the sample proteins penetrate slightly into the stacking gel $(2 \mathrm{~mm})$. Finally, the voltage was applied for stacking and separation after a second exchange of the upper buffer solution to that including TPEN, since the proteins in the stacking gel would not come into contact with TPEN in the upper buffer solution (the contaminant $\mathrm{Cu}$ in the separation gel migrates ahead of the protein bands). This MICS procedure substantially decreases the contamination level, avoiding metal-exchange and ligandexchange processes during migration. The contamination level upon electrophoresis was estimated to be in the lower ppq level according to equilibrium calculations using stability constants (see $\mathrm{ESI}_{\dagger}^{\dagger}$ ). A blank measurement was demonstrated using MICS-BN-PAGE/metal detection PAGE (Fig. S7†). The contamination level was successfully lowered to the ppt level or lower (below the detection limit of metal detection PAGE).

An example of a protein-Cu map of human serum (for a sample obtained from a healthy human female) at low temperature (see below) by MICS-BN-PAGE/metal detection
PAGE is shown in Fig. 3. No metal contamination was observed in any fraction, and the total $\mathrm{Cu}$ (summation of each fraction) was consistent with the total $\mathrm{Cu}$ determined by ICP-AES and metal detection PAGE of the serum samples (recovery $99 \pm 3 \%$, $n=10$ ). This strongly indicated that almost all $\mathrm{Cu}$ bound to proteins was detected in this system. When no TPEN was added to the upper buffer solution, the recovery was $466 \%$, which means that the penetration of the contaminant $\mathrm{Cu}$ from the upper buffer solution during electrophoresis was about $170 \%$ corresponding to $1.68 \mathrm{ppm}$ (based on results without chelating agents, 643\% recovery, vide supra) (see Fig. $\mathrm{S} 8 \dagger$ ). This revealed that contaminant $\mathrm{Cu}$ existed in the gel, eluted from the instruments, and actually migrated into the gel from the migration buffer solutions without the MICS technique.

\section{Protein-copper mapping of human serum: recovery of albumin-bound copper ions}

The results of protein-copper mapping at low temperature (vide infra) are summarized in Table 2 (the detailed results are shown in Table S3†). Most copper ions were detected in Cp fractions but few in the HSA fraction in healthy individuals $(n=10$, female and male, age 25-56), i.e., the distribution of $\mathrm{Cu}$ was approximately $100 \% \mathrm{Cp}-\mathrm{Cu}$. This result is quite inconsistent with many previous reports, in which 4-19\% of HSA-bound $\mathrm{Cu}$ ions were detected..$^{26,34,38,43-45}$ Meanwhile, it was reported by several research groups that the detection and quantitative determination of $\mathrm{HSA}-\mathrm{Cu}$ is very difficult ${ }^{28,34}$ since it is a kinetically labile metal complex. ${ }^{37,45}$

Since we doubted whether HSA-Cu could be quantitatively determined by our mapping method, the spiking tests of $\mathrm{Cu}$ in standard HSA solutions incubated with the addition of $\mathrm{Cu}$ to form HSA-Cu were examined. HSA-Cu of $40 \pm 9 \%$ was recovered from HSA fractions in the MICS-BN-PAGE/metal detection PAGE at $20{ }^{\circ} \mathrm{C}$ (see Fig. S9†). This indicates that more than half of the HSA-Cu dissociated during migration, while semi-quantitative analysis succeeded. In general, there are four possible dissociation processes for metal complexes in aqueous solution: ${ }^{74}$ acid (or base)-assisted dissociation by attacking of oxonium ion (hydroxide ion); ligand-exchange reaction by a ligand possessing coordinating ability (glycine and Tris in the buffer were the candidates in this case); metal-exchange reaction (by metal ion contaminants in this case); and spontaneous dissociation (solvolysis). In MICS-BN-PAGE, no metal-exchange process likely

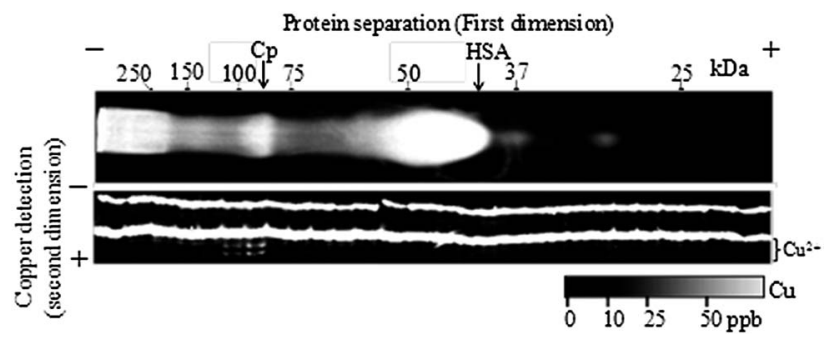

Fig. 3 Typical copper ion mapping using MICS-BN-PAGE/copper detection PAGE for human serum (a healthy female, age 25) at low temperature $\left(0^{\circ} \mathrm{C}\right.$ on the gel surface, $-5^{\circ} \mathrm{C}$ in the incubator). 
Table 2 Cu distribution in human serum samples obtained by MICS-BN-PAGE/metal detection PAGE

\begin{tabular}{|c|c|c|c|c|c|c|}
\hline Sample & Total $\mathrm{Cu} / \mathrm{ppb}^{a}$ & $\begin{array}{l}\text { Total Cu found/ppb } \\
\text { (recovery\%) }\end{array}$ & $\begin{array}{l}\text { Cp fraction/ } \\
\text { ppb (\%) }\end{array}$ & $\begin{array}{l}\text { HSA fraction/ } \\
\text { ppb (\%) }\end{array}$ & $\begin{array}{l}60 \mathrm{kDa} \text { fraction/ } \\
\mathrm{ppb}(\%)\end{array}$ & $\begin{array}{l}30 \mathrm{kDa} \text { fraction/ } \\
\mathrm{ppb}(\%)\end{array}$ \\
\hline Standard human serum ${ }^{b}$ & 1124 & $1082(96.3)$ & $1082(100)$ & n.d. $(<0.26)$ & n.d. $(<0.26)$ & n.d. $(<0.26)$ \\
\hline Human serum $(n=10)^{c}$ & $764 \pm 44$ & $\begin{array}{l}755 \pm 45 \\
(99 \pm 3)\end{array}$ & $\begin{array}{l}754 \pm 68 \\
(99.9 \pm 0.3)\end{array}$ & $\begin{array}{l}1 \pm 4 \\
(0.1 \pm 0.5)\end{array}$ & n.d. $(<0.37)$ & n.d. $(<0.37)$ \\
\hline $\begin{array}{l}\text { A human serum with the } \\
\text { addition of } 294 \mathrm{ppb} \mathrm{Cu}\end{array}$ & 965 & $952(99)$ & $649(68)$ & $187(20)$ & $116(12)$ & n.d. $(<0.37)$ \\
\hline A human serum with & 626 & $625(99.8)$ & $311(58)$ & $62(12)$ & n.d. $(<0.45)$ & $160(26)$ \\
\hline
\end{tabular}

4 times refreezing cycle ${ }^{d}$

${ }^{a}$ Determined by ICP-AES. ${ }^{b}$ Aalto Control LEVEL II N. ${ }^{c}$ Healthy individuals, age $25-56$, male and female. ${ }^{d}$ Denatured by four freeze-thaw cycles. All measurements at $293 \mathrm{~K}$.

occurs due to the metal ion contamination level being lowered to ppt or less. We investigated where the dissociation reaction occurred in the slab gel, and we also investigated: the effects of the acid-assisted dissociation reaction by changing the $\mathrm{pH}$ of the gels; the ligand-exchange reaction by changing glycine to $\gamma$-aminobutyric acid and concentrations of Tris; and the spontaneous dissociation reaction by changing the temperature (data not shown). As a result, it was revealed that HSA-Cu dissociated in the stacking gel, and spontaneous dissociation predominantly occurred (no ligand-exchange and acid-assisted dissociation was observed for $\mathrm{HSA}-\mathrm{Cu}$ ). To decelerate the spontaneous dissociation process, the temperature of the separation gel was lowered and accurately maintained at $273 \mathrm{~K}$ by steeping the stacking gel in the lower buffer solution and by using the cooling core set around the gel, which was thermostatted by circulating solvent. In addition, the set of electrophoresis instruments was placed in an incubator at $268 \mathrm{~K}$ during migration. This thorough control of the gel temperature successfully provided the quantitative recovery of HSA-Cu without dissociation ( $97 \pm 4 \%$, see Fig. S9 $\dagger$ ). An intercept corresponding to $49 \mathrm{ppb}$ of $\mathrm{Cu}$ was observed in the calibration curve, which was equivalent to the contamination $\mathrm{Cu}$ concentration value of the HSA standard solution, $50 \mathrm{ppb}$, determined by ICP-AES (Table S1 $\dagger$ ). When $294 \mathrm{ppb}$ of $\mathrm{Cu}$ was added to a human serum sample, the added $\mathrm{Cu}$ was recovered from HSA $(19.7 \%$ of total $\mathrm{Cu})$ and $60 \mathrm{kDa}(12.2 \%$ of total $\mathrm{Cu})$ fractions ( $99 \%$ recovery, Table 2). These facts strongly indicated that quantitative determination of Ex-Cu is accessible using our system, and the distribution of $\mathrm{Cu}$ in the human serum samples in Table 2 was accurate. The quantitative recovery of exchangeable $\mathrm{HSA}-\mathrm{Cu}$ is reported for the first time, to the best of our knowledge.

Based on our results, it was concluded that there is a high possibility that the widely accepted distributions of $\mathrm{Cu}$ in human serum are incorrect. The inconsistency appears to be due to the denaturing of proteins (especially $\mathrm{Cp}$ ) in the samples, as well as the dissociation processes of protein-bound $\mathrm{Cu}$ ions and the uptake of contaminant $\mathrm{Cu}$ by proteins; the impacts of none of these processes seem to have been simultaneously estimated to date. Buckley et al. recently reported that $\mathrm{Cp}-\mathrm{Cu}$ is easily denatured even at $-10{ }^{\circ} \mathrm{C}(\mathrm{Cp}-\mathrm{Cu}$ is stable at below $-60{ }^{\circ} \mathrm{C}$ ), denaturing is irreversible, and cycles of freezing and refreezing also induce denaturing. Cu released from denatured $\mathrm{Cp}$ would bind with other proteins such as HSA. In our case, the serum samples were frozen just after centrifugation at $-40{ }^{\circ} \mathrm{C}$ (see the Procedure section), and no refrozen samples were used to avoid denaturing effects. In fact, when using a deliberately denatured human serum sample via four freeze-thaw cycles, the amount of $\mathrm{Cp}-\mathrm{Cu}$ clearly decreased, and the $\mathrm{HSA}-\mathrm{Cu}$ concentration increased (see Table 2 and Fig. S10†). In addition, $\mathrm{Cu}$ ions bound with an unknown protein of $30 \mathrm{kDa}$ were observed. Thus, it seems that there are multiple effects on the results reported previously. A value of $3.4 \%$ of Ex-Cu in plasma, which was the closest to our results, was reported after careful handling of samples in terms of denaturation by using the isotope dilution method. ${ }^{45}$ In this method, contamination with metal ions in the reagents would be less than in the separation methods, while the Ex-Cu content in serum should be lower than in plasma since most $\mathrm{Tc}-\mathrm{Cu}$ is lost from serum into clots. ${ }^{48}$

\section{Conclusions}

Using the MICS-BN-PAGE/metal detection PAGE system, the accurate distribution of $\mathrm{Cu}$ in human serum was investigated by quantitative determination of exchangeable HSA-Cu. Metal detection PAGE is suitable for determination of ultratrace metal ions in many cut gel fractions after slab gel electrophoresis, including two dimensional gels, because simultaneous analysis of many samples is accessible with re-concentration of the diluted elutes. ${ }^{35}$ Since other metal ions like $\mathrm{Fe}$ and $\mathrm{Hg}$ were also detected by metal detection PAGE using other metal probes with different chelating structures (data not shown), their distribution in biological samples will be reported in our next publication. Also, this is the first report of contaminant metal-free separation media for metalloproteins with suppression of the dissociation processes, in which the protein-bound copper with slower dissociation kinetics than the exchangeable $\mathrm{HSA}-\mathrm{Cu}$ can be detected. As such, MICS-BN-PAGE provides lots of potential to detect metal ions including exchangeable ones. Future experiments will focus on determination of trace metal ions binding with metalloproteins in various biological samples by using the MICS-BN-PAGE/metal detection PAGE system.

\section{Acknowledgements}

This research was supported by a Grant-in-Aid for Young Scientists (B) no. 23750077 and no. 21750072 from the Ministry 
of Education, Culture, Sports, Science and Technology of Japan, and by Asahi Glass Foundation, and Foundation NAGASE Science Technology Development.

\section{Notes and references}

1 K. J. Waldron, J. C. Rutherford, D. Ford and N. J. Robinson, Nature, 2009, 460, 823.

2 H. Haraguchi, J. Anal. At. Spectrom., 2004, 19, 5.

3 A. Cvetkovic, A. L. Menon, M. P. Thorgersen, J. W. Scott, F. L. Poole II, F. E. Jenney Jr, W. A. Lancaster, J. L. Praissman, S. Shanmukh, B. J. Vaccaro, S. A. Trauger, E. Kalisiak, J. V. Apon, F. Siuzdak, S. M. Yannone, J. A. Tainer and M. W. W. Adams, Nature, 2010, 466, 779.

4 J. Szpumar, Analyst, 2005, 130, 442.

5 W. Shi and M. R. Chance, Cell. Mol. Life Sci., 2008, 65, 3040.

6 I. Worms, D. F. Simon, C. S. Hassler and K. J. Wilkinson, Biochimie, 2006, 88, 1721.

7 Y. Ha, O. G. Tsay and D. G. Ghurchill, Monatsh. Chem., 2011, $142,385$.

8 J. S. Garcia, C. S. Magalhaex and M. A. Z. Arruda, Talanta, 2006, 69, 1.

9 J. Szpunar, Analyst, 2000, 125, 963.

10 R. Lobinski, C. Moulin and R. Ortega, Biochimie, 2006, 88, 1591.

11 A. S. González, J. R. Encinar, A. M. C. Roldán, J. M. M. Gayón and A. S. Medel, Anal. Chem., 2008, 80, 8702.

12 S. Trümpler, W. Lohmann, B. Meermann, W. Buscher, M. Sperling and U. Karst, Metallomics, 2009, 1, 87.

13 B. Deng, P. Zhu, Y. Wang, J. Feng, X. Li, X. Xu, H. Lu and Q. Xu, Anal. Chem., 2008, 80, 5721.

14 B. Deng, X. Li, P. Zhu, X. Xu, Q. Xu and Y. Kang, Electrophoresis, 2008, 29, 1534.

15 Y. Li, X. Yin and X. Yan, Anal. Chim. Acta, 2008, 615, 105.

16 A. Nguyen and M. Moini, Anal. Chem., 2008, 80, 7169.

17 M. G. Aňorbe, J. Messerschmidt, I. Feldmann and N. Jakubowski, J. Anal. At. Spectrom., 2007, 22, 917.

18 J. S. Becker, R. Lobinski and J. S. Becker, Metallomics, 2009, 1, 312 .

19 M. Ferre, O. V. Golyshina, A. Beloqui, P. N. Golyshin and K. N. Timmis, Nature, 2007, 445, 91.

20 S. D. Smith, Y. She, E. A. Roberts and B. Sarkar, J. Proteome Res., 2004, 3, 834.

21 B. Kastenholz, Protein Pept. Lett., 2006, 13, 503.

22 B. Katenholz, Protein Pept. Lett., 2007, 14, 389.

23 A. M. Sevcenco, M. W. Pinkse, H. T. Wolterbeek, P. D. Verhaert, W. R. Hagen and P. L. Hagedoorn, Metallomics, 2011, 3, 1324.

24 M. Malavaolta, F. Piacenza, A. Basso, R. Giacconi, L. Costarelli, S. P. Paoli and E. Mocchegiani, Anal. Biochem., 2012, 421, 16.

25 C. S. Muñiz, J. M. M. Gayón, J. I. G. Alonso and A. S. Muniz, J. Anal. At. Spectrom., 2001, 16, 587.

26 T. Hasegawa, Y. Wakita, Y. Zhu, H. Matsuura, H. Haraguchi and T. Umemura, Bull. Chem. Soc. Jpn., 2007, 80, 503.

27 E. Z. Jahromi, W. White, Q. Wu, R. Yamdagni and J. Gailer, Metallomics, 2010, 2, 460.
28 S. E. Balkhi, J. Poupon, J. Trocello, F. Massicot, F. Woimant and O. Laprévote, Anal. Chem., 2010, 82, 6904.

29 C. C. Chéry, D. Günther, R. Cornelis, F. Vanhaecke and L. Moens, Electrophoresis, 2003, 24, 3305.

30 M. S. Jimenez, L. Rodriguez, M. T. Gomex and J. R. Castillo, Talanta, 2010, 81, 241.

31 M. S. Jimenez, M. T. Gomez, L. Rodriguez, L. Martinez and J. R. Castillo, Anal. Bioanal. Chem., 2009, 393, 699.

32 A. Raab, B. Pioselli, C. Munro, J. Thomas-Oates and J. Feldmann, Electrophoresis, 2009, 30, 303.

33 S. A. Manley, S. Byrns, A. W. Lyon, P. Brown and J. Gailer, J. Biol. Inorg. Chem., 2009, 14, 61.

34 K. Inagaki, N. Mikuriya, S. Morita, H. Haraguchi, Y. Nakahara, M. Hattori, T. Kinosita and H. Saito, Analyst, 2000, 125, 197.

35 In the gel electrophoresis instruments employed in this work, up to 160 samples can be simultaneously applied with four electrophoresis chambers and eight gel plates. Migration time per sample is less than a few minutes.

36 B. A. Fowler, G. F. Nordberg, M. Nordberg and L. Friberg, Handbook on the Toxicology of Metals, Academic Press, 3rd edn, 2007, ch. 26, p. 529.

37 J. M. Walshe, Q. J. Med., 2012, 105, 419.

38 P. L. Wirth and M. C. Linder, JNCI, J. Natl. Cancer Inst., 1985, $75,277$.

39 S. S. S. J. Ahmed and W. Santosh, PLoS One, 2010, 5, e11252. 40 G. N. L. Jameson, Monatsh. Chem., 2011, 142, 325.

41 G. Arena, G. Pappalardo, I. Sovago and E. Rizzarelli, Coord. Chem. Rev., 2012, 256, 3.

42 P. Faller and C. Hureau, Dalton Trans., 2009, 1080.

43 L. Barrow and M. S. Tanner, Eur. J. Clin. Invest., 1988, 18, 555. 44 (a) M. M. Wintrobe, G. E. Cartwright and C. J. Gubler, J. Nutr., 1953, 29, 395; (b) M. M. Wintrobe and G. E. Cartwright, Am. J. Clin. Nutr., 1964, 14, 224; (c) G. W. Evans and R. E. Wiederanders, Am. J. Physiol., 1967, 213, 1183.

45 W. T. Buckley, A. Richard and A. Vanderpool, Biometals, 2008, 21, 601.

46 K. D. Rainsford, R. Milanino, J. R. J. Sorenson and G. P. Velo, Copper and Zinc in Inflammatory and Degenerative Diseases, Kluwer Academic Publishers, 1998, ch. 62, p. 24.

47 M. E. Shils, M. Shike, A. C. Ross, B. Caballero and R. J. Cousins, Modern Nutrition In Health And Disease, Lippeincott Williams \& Wilkins, 10th edn, 2005, p. 295.

48 A. Cabrera, E. Alonzo, E. Sauble, Y. L. Chu, M. C. Linder, D. S. Sato and A. Z. Mason, Biometals, 2008, 21, 525.

49 S. Saito, Y. Nakano, A. Hikichi, R. Suzuki, K. Yoshioto, M. Maeda, M. Aoyama and M. Shibukawa, Analyst, 2011, 136, 2697.

50 U. K. Laemmli, Nature, 1970, 227, 680.

51 B. J. Davis, Ann. N. Y. Acad. Sci., 1964, 121, 404.

52 M. Urbánek, L. Křivánková and P. Boček, Electrophoresis, 2003, 24, 466.

53 S. Saito, R. Suzuki, N. Danzaka, A. Hikichi, K. Yoshimoto, M. Maeda and M. Aoyama, Electrophoresis, 2007, 14, 2448.

54 S. Saito, J. Shimidzu, K. Yoshimoto, M. Maeda and M. Aoyama, J. Chromatogr., A, 2007, 1140, 230. 
55 S. Saito, S. Takeuchi, K. Yoshimoto, M. Maeda and M. Aoyama, Analyst, 2007, 132, 237.

56 S. Saito, S. Sasamura and S. Hoshi, Analyst, 2005, 130, 659.

57 S. Saito and H. Hoshino, Anal. Bioanal. Chem., 2004, 378, 1644.

58 S. Saito, Bunseki Kagaku, 2011, 60, 773.

59 D. L. Holmes and N. C. Stellwagen, Electrophoresis, 1991, 12, 253.

60 D. L. Holmes and N. C. Stellwagen, Electrophoresis, 1991, 12, 612.

61 M. Shibukawa, K. Aoyagi, R. Sakamoto and K. Oguma, J. Chromatogr., A, 1999, 832, 17.

62 M. Shibukawa, Bunseki Kagaku, 2006, 55, 149.

63 N. Kameta, H. Minamikawa, Y. Someya, H. Yui, M. Masuda and T. Shimizu, Chem.-Eur. J., 2010, 16, 4217.

64 G. Anderegg, R. Arnaud-Neu, R. Delgado, J. Felcman and K. Popov, Pure Appl. Chem., 2005, 77, 1445.

65 S. Y. Lau and B. Sarkar, J. Biol. Chem., 1971, 246, 5938.

66 S. Y. Lau, J. Biol. Chem., 1971, 246, 5938.

67 I. Wittig, H. P. Braun and H. Schagger, Nat. Protoc., 2006, 1, 418.

68 The contamination level of $\mathrm{Cu}$ from vacuum blood collection tubes was at sub-ppb, investigated by blank tests. This contamination concentration is $0.1 \%$ or lower than total
$\mathrm{Cu}$ concentration in human serum. Therefore, the tube was not a major contamination source.

69 Such ppb level contamination of metal ions was a surprise to us. However, it must be noted that contamination on the order of $\mathrm{ppb}$ is possible according to information from reagent suppliers. For example, a high contaminant metal content $(<5 \mathrm{ppm}$ for each $\mathrm{Cu}$ and $\mathrm{Fe}$ ) in polyacrylamide powder (electrophoresis grade) purchased from Sigma is characterized in the specification sheet.

70 In fact, the elevated baseline and saddle-shaped peaks of chromatograms frequently observed were possibly due to metal contamination, and unreasonable distributions were obtained for biological samples. For examples, see ref. 2, 18,24 and 26

71 I. J. Arnquist and J. A. Holcombe, Spectrochim. Acta, Part B, 2012, 76, 140.

72 P. D. Angelo, E. Bottari, M. R. Festa, H. F. Nolting and N. V. J. Pavel, J. Phys. Chem., 1998, 102, 3114.

73 G. Anderegg, E. Hubmann, N. G. Poddr and F. Wenk, Helv. Chim. Acta, 1977, 60, 123.

74 (a) S. F. Lincoln and A. E. Merbach, Advances in Inorganic Chemistry, Academic Press, New York, 1995, vol. 42; (b) A. E. Martell, Coordination Chemistry, American Chemical Society, Washington, DC, 1978, vol. 2. 